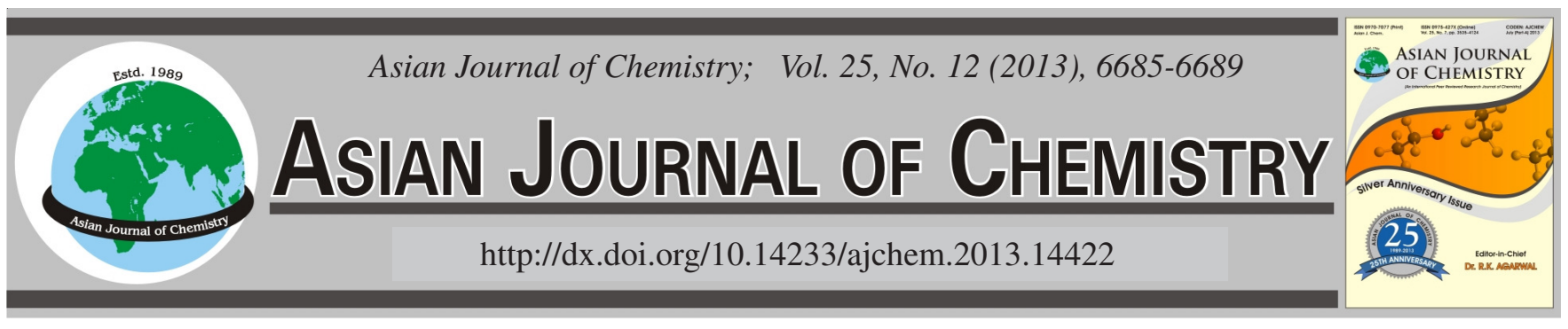

\title{
Separation and Determination of Sulfonamides by Microchip Electrophoresis with Laser-Induced Fluorescence
}

\author{
FAng-Yuan Chen, Peng Li, Yan-Hong Wang and Hong-Zhen Lian*
}

State Key Laboratory of Analytical Chemistry for Life Science, School of Chemistry \& Chemical Engineering and Center of Materials Analysis, Nanjing University, Nanjing 210093, P.R. China

*Corresponding author: E-mail: hzlian@nju.edu.cn

(Received: 8 August 2012;

Accepted: 27 May 2013)

AJC-13549

\begin{abstract}
A simple and sensitive microfluidic capillary electrophoresis method with laser induced fluorescence detection was developed for the analysis of sulfonamides using fluorescein isothiocyanate as derivatization reagent. The performance of the system was demonstrated through the separation and determination of sulfamethazine, sulfamerazine and sulfamethoxazole in a running buffer solution containing $20 \mathrm{mmol} / \mathrm{L}$ borax ( $\mathrm{pH} 9.2$ ) with $15 \%$ (v/v) ethanol. The injection and separation voltages, the concentration of borax, $\mathrm{pH}$ of the buffer and the content of ethanol in running buffer were optimized to get great influence on the separation. This proposed method showed satisfactory sensitivity with the limits of detection $(\mathrm{S} / \mathrm{N}=3)$ of 0.01 to $0.04 \mu \mathrm{mol} / \mathrm{L}$ for the sulfonamides. The method also exhibited very good reproducibility with the relative standard deviations of not more than 9.2 and $2.2 \%$ for fluorescence intensity and migration time, respectively. The analysis was achieved within only $1.6 \mathrm{~min}$.
\end{abstract}

Key Words: Sulfonamides, Fluorescein isothiocyanate, Microchip electrophoresis-laser induced fluorescence.

\section{INTRODUCTION}

Sulfonamides are synthetic antimicrobial drugs, which are used in aquaculture and animal husbandry and as medicines for human beings to treat diseases such as gastrointestinal and respiratory tract infections ${ }^{1}$. Represented by sulfamethazine (SMZ), they have been widely used for clinical and veterinary practice for decades, but abuse of them or insufficient withdrawal time would lead to accumulation of these drugs in animal or human tissues ${ }^{2,3}$. Sulfonamides at high levels may cause allergy, carcinogenesis and antibiotic-resistance of bacteria, which attracted the attention of public ${ }^{4-6}$. Therefore, it is important to develop simple, accurate and sensitive methods for the detection of sulfonamides.

Various approaches are reported in literatures for the determination of SMZ in combination with other sulfonamides such as sulfanilamide (SAM), sulfaquinoxaline (SQX), sulfadimethoxine (SDM), sulfamerazine (SMR), sulfathiazole (STZ), sulfadiazine (SDZ) and sulfamethoxazole (SMX), etc., which include spectrophotometry ${ }^{7}$, flow injection analysis ${ }^{8,9}$, voltammetry $^{10,11}$, immunoassay ${ }^{12-14}$, gas chromatography-mass spectrometry (GC-MS $)^{15,16}$, high performance liquid chromatography (HPLC) ${ }^{17-19}$ and chemometrics methods ${ }^{20}$.

Microfluidic technologies are powerful tools to perform chemical and biochemical assays. Microchips have been successfully applied in a variety of electrically driven separation techniques since they were introduced in the early $1990 \mathrm{~s}^{21-23}$. The separation performance of microchip electrophoresis (MCE) was found to be similar to conventional capillary electrophoresis in spite of geometrical restrictions. The prominent advantages of MCE include shorter analysis time, lower consumption of sample and reagent, good integration and highthrough-put screening ${ }^{24-26}$. Laser induced fluorescence (LIF) provides high sensitivity and becomes the most important detection technique in $\mathrm{MCE}^{27-29}$. However, because very few analytes themselves can emit enough fluorescence, a derivatization procedure with a suitable fluorescent reagent to produce a fluorescent adduct is necessary for the development of a MCE-LIF method. Wang et al., have performed the separation and detection of SAM, SMX, SMZ and SQX using MCELIF $^{30}$. However, they didn't consider the separation of SMZ and SMR, which have the similar structure only with the difference of a 6-position methyl group (Fig. 1, upper). In addition, Chu et al. ${ }^{31}$ determined SMZ, SDM, SMR, STZ, SDZ and SMX based on capillary zone electrophoresis with electrochemical detection. However, a little bit high detection limits were obtained ranged from $9.3 \times 10^{-8}-1.3 \times 10^{-7} \mathrm{~g} / \mathrm{mL}$ for SMZ, SMR and SMX. Separation and determination of SMZ and SMR at low concentration is a challenging task of great importance. In this paper, a simple MCE-LIF method was developed for 
simultaneously separating and detecting three commonly used sulfonamides, SMZ, SMR and SMX, with fluorescein isothiocyanate (FITC) as fluorescent reagent (Fig. 1, lower).
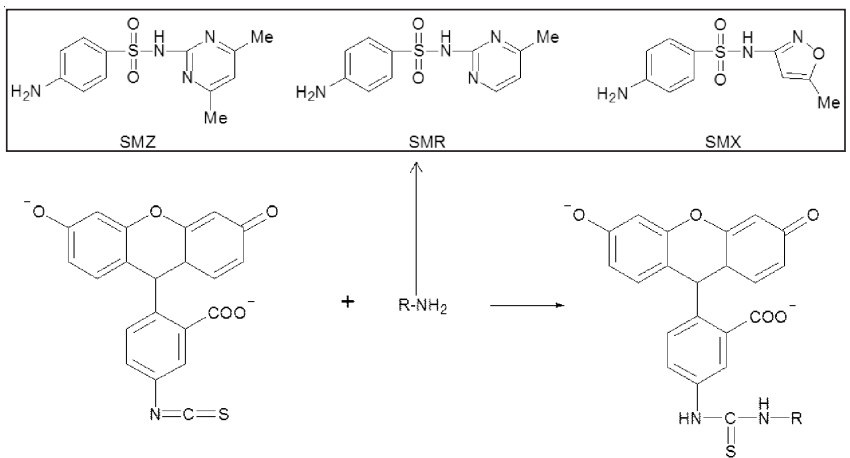

Fig. 1. Molecular structures of SMZ, SMR and SMX (upper) and the reaction of FITC with sulfonamide (lower). $\mathrm{R}-\mathrm{NH}_{2}$ represents the sulfonamide

\section{EXPERIMENTAL}

The glass microchip was provided by Dalian Institute of Chemical Physics, Chinese Academy of Sciences (Dalian, China). Channel cross-section was close to a rectangle structure (70 $\mu \mathrm{m}$ width, $15 \mu \mathrm{m}$ depth); the detection was performed 45 $\mathrm{mm}$ downstream from the cross-section on the microchip. The four reservoirs were $3.0 \mathrm{~mm}$ in diameter and $1.5 \mathrm{~mm}$ in depth (Fig. 2a). An intelligent four-path-high-voltage electric device (IFED) and a chip-based CE LIF detector (LIF-D) are provided by Professor Qing-ling Li (Shandong Normal University, Jinan, China) as presented in Fig. 2b. Confocal optics mode structure was chosen as optics collection system of LIF-D. A $473 \mathrm{~nm}$ semiconductor double-pumped solid-state laser (SDPSS, MBL-20) from Changchun New Industries Optoelectronics Tech. (Changchun, China) was used as the excitation source. The laser beam was reflected and focused on the detection point; emission fluorescence was optically filtered by a $525 \pm$ $10 \mathrm{~nm}$ narrowband filter from Omega Optical (Brattleboro, VT, USA) before being detected by a photomultiplier (PMT, CR131) from Hamamatsu (Iwata, Japan). Signal acquisition and processing were operated on a CT-22 data acquisition card from Qianpu Data (Shanghai, China), with a sampling frequency of $20 \mathrm{~Hz}$.

Fluorescein isothiocyanate (FITC), sulfamethazine (SMZ), sulfamerazine (SMR) and sulfamethoxazole (SMX) were all purchased from Sigma-Aldrich (St. Louis, Mo, USA). Ethanol, 2,5-dimethyl formamide (DMF), triethylamine (TEA) and borax were of analytical-reagent grade, provided by Nanjing Chemical Reagent (Nanjing, China). De-ionized water was used throughout the experiments. Buffer solutions were prepared by diluting the borax stock solution $(1 \mathrm{~mol} / \mathrm{L}, \mathrm{pH}$ 9.2) with water and then adjusted with $1 \mathrm{~mol} / \mathrm{L} \mathrm{HCL}$ or $1 \mathrm{~mol} /$ $\mathrm{L} \mathrm{NaOH}$ to the required $\mathrm{pH}$. All buffer solutions were filtered through a $0.22 \mu \mathrm{m}$ filter from Hanbon Sci. \& Tech. (Huaian, China) before use.

Derivatization: Fluorescein isothiocyanate solution was prepared by dissolving $12 \mathrm{mg}$ in $5.7 \mathrm{~mL} \mathrm{DMF}$ and $0.3 \mathrm{~mL}$ TEA. FITC working solution $\left(2.0 \times 10^{-4} \mathrm{~mol} / \mathrm{L}\right)$ was freshly diluted from the solution by DMF and TEA (19:1, v/v). SMZ (112 mg), SMR (105 mg) and SMX (102 mg) were respectively
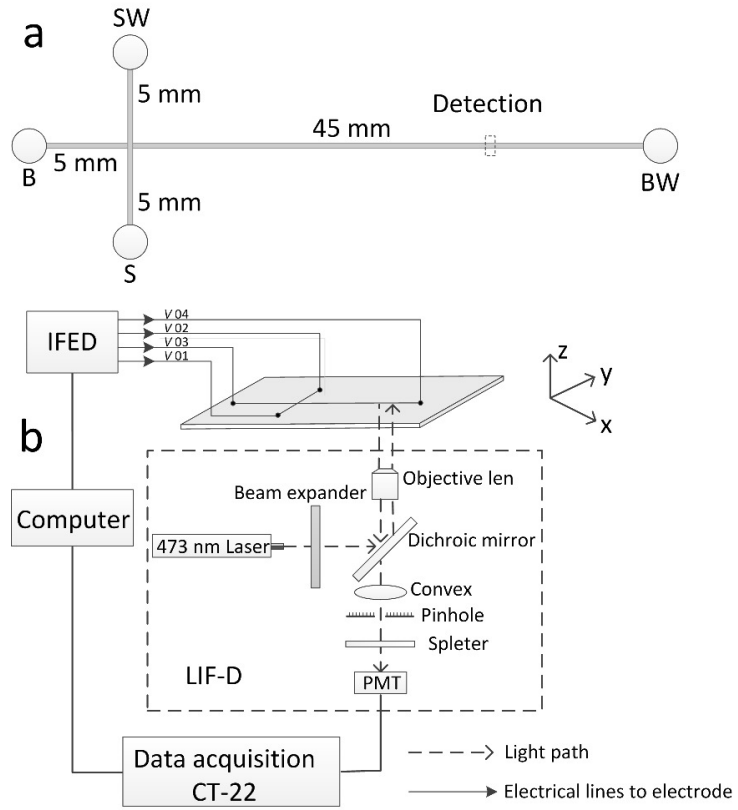

Fig. 2. Schematic diagrams of (a) channels design of the microchip and (b) MCE experimental system. S, sample reservoir; SW, sample waste reservoir; B, buffer reservoir; BW, buffer waste reservoir; IFED, intelligent four-path-high-voltage electric device; LIF-D, LIF detector

dissolved in $4 \mathrm{~mL}$ DMF. Mixed standard solutions were then obtained by diluting the corresponding stock solutions by 20 mmol/L borax buffer solution ( $\mathrm{pH}$ 9.2). $30 \mu \mathrm{L}$ FITC working solution was added to $1 \mathrm{~mL}$ mixed standard solution, constantly stirring in $1.5 \mathrm{~mL}$ centrifuge tube, kept in a dark place overnight at room temperature ${ }^{32}$.

Microchip procedure: Microfluidic manipulations were carried out according to the following steps. $20 \mathrm{mmol} / \mathrm{L}$ borax buffer solution ( $\mathrm{pH} 9.2$ ) containing $15 \%(\mathrm{v} / \mathrm{v})$ ethanol was used as running buffer solution. The microchannels of the chip were firstly rinsed with $1 \mathrm{mmol} / \mathrm{L} \mathrm{NaOH}$ for $15 \mathrm{~min}$, then water for $15 \mathrm{~min}$ and running buffer solution for $10 \mathrm{~min}$. The laser beam was adjusted to focus at $45 \mathrm{~mm}$ position in the separation channel near the channel cross. Four platinum electrodes $(0.1 \mathrm{~mm}$ in diameter) randomly chosen from IFED were inserted into the corresponding reservoirs, respectively.

Ten microliter of running buffer solution was filled into reservoirs B, BW and SW, respectively and $10 \mu \mathrm{L}$ of sample solution to reservoir $\mathrm{S}$. The sample-pinched injection and electrophoresis separation were controlled by the voltage output of the IFED for each reservoir. During the pinched injection for $20 \mathrm{~s}, 400 \mathrm{~V}$ was applied to reservoir S; 230 and $280 \mathrm{~V}$ were applied to reservoirs B and BW, respectively, while reservoir SW grounded. During separation, $2200 \mathrm{~V}$ was applied to reservoir B, $1400 \mathrm{~V}$ to reservoirs $\mathrm{S}$ and $\mathrm{SW}$ with reservoir BW grounded. Experiments were duplicated for three times under each separation condition.

\section{RESULTS AND DISCUSSION}

Selection of derivatization medium: The reaction was kept at room temperature overnight ${ }^{32}$. This is because at high temperature, FITC was unstable and transformed into more complex products. In our experiment, DMF and TEA were 
chosen as solvents of derivatization. It was found that there were few FITC-sulfonamides detected in the resultant without TEA.

Effect of injection and separation potentials: For a given channel length, injection and separation voltages determine the electric field strength, which influence both the amount of driven sample and the velocity of electrosmotic flow (EOF), which in turn determine the peak size and migration time of analytes. $5 \times 10^{-7} \mathrm{~mol} / \mathrm{L}$ FITC was used as the pilot analyte and $20 \mathrm{mmol} / \mathrm{L}$ borax (pH 9.2) containing $15 \%$ (v/v) ethanol as the running buffer. During sample loading, FITC was electroosmotically transported from reservoir $\mathrm{S}$ into reservoir SW using the potentials listed in Table-1. Running buffer from reservoirs B and BW served to electrokinetically confine the sample in the cross intersection. Keeping reservoir $\mathrm{S}$ voltage $400 \mathrm{~V}$ and changing voltages of reservoirs B and BW, we found that in case 3 when 230 and $280 \mathrm{~V}$ were respectively applied to reservoirs B and BW, the peak shape was better than those in cases 1 and 2 . After $20 \mathrm{~s}$ injection, applied potentials were then switched to separation mode and the sample plug was launched into the separation channel. With the same injection voltage, increasing reservoir $\mathrm{S} / \mathrm{SW}$ voltage or decreasing reservoir B voltage would bring worse peak shape caused by tailing.

Effect of injection time: The injection conditions on the microchip are strongly dependent on the injection time, which affects both fluorescence intensity and peak shape of FITCderivatized sulfonamides. The effect of injection time was studied by varying injection time from 10-30 s. It was found that the fluorescence intensity increased with increasing injection time from 10 to $20 \mathrm{~s}$. When the injection time was longer than $20 \mathrm{~s}$, however, peak height was nearly invariable and peak broadening became more obvious. In this experiment, $20 \mathrm{~s}$ was chosen as the optimum injection time.

Effect of running buffer concentration and pH: In microchip electrophoresis analysis, both concentration and $\mathrm{pH}$ of running buffer play important roles. The ionic strength of the running buffer solution is directly related to the concentration of borax. In this experiment, the borax concentration was chosen in the range of $5-30 \mathrm{mmol} / \mathrm{L}$ at $\mathrm{pH} 9.2$, containing $15 \%(\mathrm{v} / \mathrm{v})$ ethanol. The experiments indicated that derivatives of sulfonamides with FITC migrated more slowly at higher concentrations of borax. When borax concentration was below $20 \mathrm{mmol} / \mathrm{L}$, three derivatives couldn't be separated and especially SMZ-FITC and SMR-FITC merged together. With the increase of borax concentration, migration time became longer.
The resolutions improved significantly with increasing buffer concentration but leveled off at higher concentrations, possibly due to excessive Joule heating. The higher buffer concentration led to greater electric currents as shown in Fig. 3a and more intensive Joule heating, which might bring noise to baseline, resulting in unstable electrokinetic conditions. In order to obtain higher resolution and avoid excessive Joule heating, a buffer concentration of $20 \mathrm{mmol} / \mathrm{L}$ was considered to be a good choice.
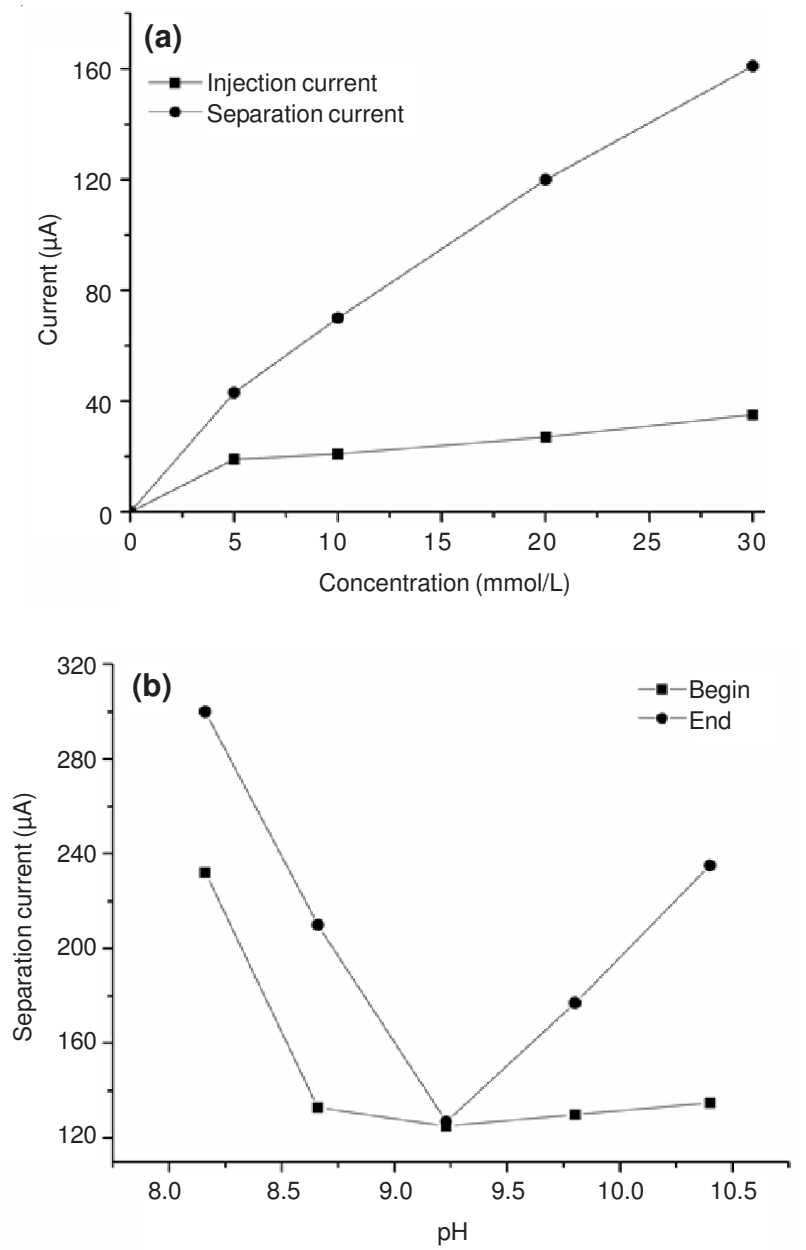

Fig. 3. (a) Influence of borax concentration on injection and separation currents, buffer $\mathrm{pH} 9.2$; (b) Influence of borax buffer $\mathrm{pH}$ on separation current, borax concentration $20 \mathrm{mmol} / \mathrm{L}$. Ethanol content in the running buffer: $15 \%(\mathrm{v} / \mathrm{v})$; Injection voltage: S: $400 \mathrm{~V}, \mathrm{SW}$ : $0 \mathrm{~V}, \mathrm{~B}: 230 \mathrm{~V}, \mathrm{BW}: 280 \mathrm{~V}$; separation voltage: S/SW: $1400 \mathrm{~V}$, B: $2200 \mathrm{~V}$, BW: $0 \mathrm{~V}$; injection time: $20 \mathrm{~s}$; concentrations of analytes: $5.0 \times 10^{-7} \mathrm{~mol} / \mathrm{L}$, each; FITC: $6 \times 10^{-6} \mathrm{~mol} / \mathrm{L}$

TABLE-1

INJECTION VOLTAGE, SEPARATION VOLTAGE, PEAK HEIGHT, TAILING FACTOR, AND ASYMMETRY FACTOR

\begin{tabular}{|c|c|c|c|c|c|c|c|}
\hline \multirow{2}{*}{ No. } & \multicolumn{2}{|c|}{ Injection voltage (V) } & \multicolumn{2}{|c|}{ Separation voltage (V) } & \multirow{2}{*}{$\begin{array}{c}\text { Peak height } \\
(\mathrm{mV})\end{array}$} & \multirow{2}{*}{ Tailing factor ${ }^{\mathrm{a}}$} & \multirow{2}{*}{$\begin{array}{c}\text { Asymmetry } \\
\text { factor }^{\mathrm{b}}\end{array}$} \\
\hline & B & BW & S/SW & B & & & \\
\hline 1 & 280 & 360 & 1400 & 2200 & 17.3 & 0.89 & 1.29 \\
\hline 2 & 200 & 240 & 1400 & 2200 & 24.0 & 0.98 & 0.98 \\
\hline 3 & 230 & 280 & 1400 & 2200 & 23.5 & 1.00 & 1.02 \\
\hline 4 & 230 & 280 & 1600 & 2200 & 26.1 & 1.66 & 0.48 \\
\hline 5 & 230 & 280 & 1400 & 2000 & 13.8 & 1.52 & 0.57 \\
\hline
\end{tabular}

${ }^{a}$ The tailing factor is defined as the distance from the front slope of the peak to the back slope divided by twice the distance from the center line of

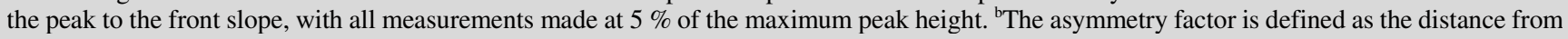
the center line of the peak to the back slope divided by the distance from the center line of the peak to the front slope, with all measurements made at $10 \%$ of the maximum peak height ${ }^{33}$. 
The influence of $\mathrm{pH}$ of the running buffer on separation was tested using $20 \mathrm{mmol} / \mathrm{L}$ borax buffer solution from $\mathrm{pH}$ 8.2 to 10.4 , containing $15 \%(\mathrm{v} / \mathrm{v})$ ethanol. The resolution didn't show any obvious improvement, whether $\mathrm{pH}$ was lower or higher than 9.2. However, the currents increased significantly, which produced excessive Joule heating and strong noise, shown in Fig. 3b. Therefore, it seemed reasonable to choose $20 \mathrm{mmol} / \mathrm{L}$ and 9.2 as the optimal concentration and $\mathrm{pH}$ of borax buffer solution, respectively.

Effect of ethanol concentration: Ethanol with abundant hydroxyl groups was selected in this work. It was added to the running buffer to act as a viscosity regulator and surface charge modifier $^{34,35}$. The effect of ethanol on FITC-derivatized sulfonamides separation was studied by ranging the ethanol content from 0 to $25 \%$ (v/v), whereas borax concentration was maintained at $20 \mathrm{mmol} / \mathrm{L}$ and $\mathrm{pH}$ at 9.2. As shown in Fig. 4, both peak shape and resolution of SMZ-FITC, SMR-FITC and SMX-FITC, as well as FITC were improved greatly, with increasing ethanol concentration to $15 \%$. When ethanol concentration increased from 15 to $25 \%$, fluorescence intensity decreased greatly and migration time extended from 93 to $152 \mathrm{~s}$. Hence, a pH of 9.2 and a concentration of $20 \mathrm{mmol} / \mathrm{L}$ borax buffer with $15 \%(\mathrm{v} / \mathrm{v})$ ethanol were finally selected for good peak shape and low current (Fig. 4c).

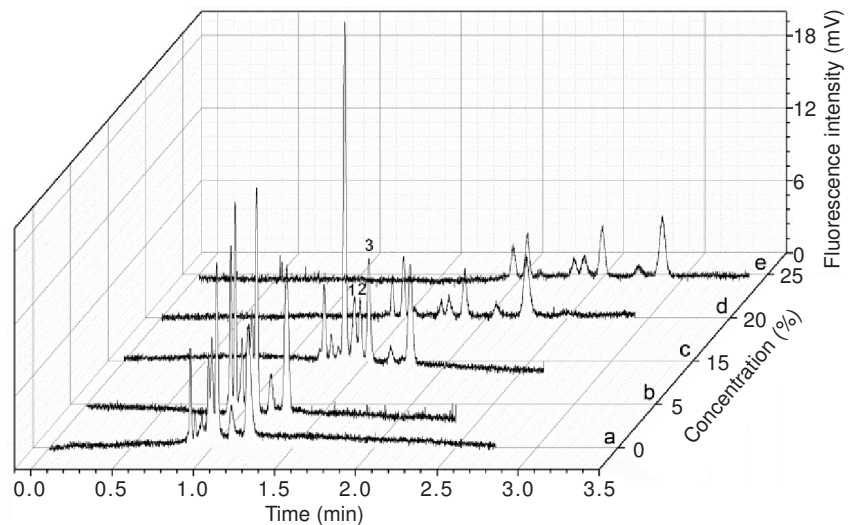

Fig. 4. Effect of ethanol concentration on FITC-sulfonamide separation: $20 \mathrm{mmol} / \mathrm{L}$ borax buffer, $\mathrm{pH}$ 9.2; all other conditions were the same as in Fig. 3. In Fig. 4c, 1: SMZ-FITC; 2: SMR-FITC; 3: SMXFITC; other peaks were from FITC

Linearity, limits of detection, limits of quantitation and reproducibility: Under the optimized conditions, the typical electrophorogram of FITC-sulfonamides is shown in Fig. 4c. It is found that the FITC derivatives of SMZ, SMR and SMX were separated clearly. A series of mixed standard solutions of SMZ, SMR and SMX, ranging from 0.05 to $1.25 \mu \mathrm{mol} / \mathrm{L}$, were analyzed. There are six series concentrations used for SMZ, SMX and SMX. The fluorescence intensity and concentration of each analyte were subjected to regression analysis to calculate the calibration equations and correlation coefficients. The limits of detection (LODs) and limits of quantitation (LOQs), calculated on the basis of $\mathrm{S} / \mathrm{N}$ ratios of 3 and 10, respectively (Table-2). Each mixed standard solution was analyzed for 4 times. The precisions of fluorescence intensity and migration time were evaluated by relative standard deviations (RSDs). The RSDs of fluorescence intensity were less than 8.7, 9.2 and $6.5 \%$ and those of migration time were less than 2.2, 2.1 and $2.0 \%$, respectively, for FITC derivatives of SMZ, SMR and SMX.

\section{Conclusion}

A separation and detection method for three sulfonamides SMZ, SMR and SMX was developed using MCE-LIF technique in combination with FITC derivatization. The reaction, injection and separation conditions were optimized to improve the sensitivity, as well as to separate FITC-derivatized SMZ, SMR and SMX, especially for FITC-SMZ and FITC-SMR with very similar structures in a short running time.

\section{ACKNOWLEDGEMENTS}

This work was supported by National Natural Science Fund of China (90913012), National Basic Research Program of China (973 Program, 2011CB911003, 2009CB421601), and National Science Funds for Creative Research Groups (21121091).

\section{REFERENCES}

1. S. Wang, H.Y. Zhang, L. Wang, Z.J. Duan and I. Kennedy, Food Addit. Contam., 23, 362 (2006).

2. A. Krivohlavek, Z. Smit, M. Bastinac, I. •untar and F. Plavšc-Plavšic, J. Sep. Sci., 28, 1434 (2005).

3. C. Nebot, P. Regal, J. Miranda, A. Cepeda and C. Fente, J. Chromatogr. Sci., 50, 414 (2012).

4. C.C. Brackett, Curr. Allergy Asthma Rep., 7, 41 (2007).

5. C.C. Brackett, H. Singh and J.H. Block, Pharmacotherapy, 24, 856 (2004).

6. B.A. Hemstreet and R.L. Page, Pharmacotherapy, 26, 551 (2006).

7. S.M. Sabry, Anal. Lett., 39, 2591 (2006).

8. G.K. Kristiansen, R. Brook and G. Bojesen, Anal. Chem., 66, 3253 (1994).

9. G. Lattanzio, A.M. Garcia-Campana, J.J. Soto-Chinchilla, L. GámizGracia and S. Girotti, J. Pharm. Biomed. Anal., 46, 381 (2008).

10. A.M. Garcia-Campana, L. Gamiz-Gracia, F.J. Lara, M. del Olmo Iruela and C. Cruces-Blanco, Anal. Bioanal. Chem., 395, 967 (2009).

11. H. Sangjarusvichai, W. Dungchai, W. Siangproh and O. Chailapakul, Talanta, 79, 1036 (2009).

12. J. Adrian, S. Pasche, J.M. Diserens, F. Sánchez-Baeza, H. Gao, M.P. Marco and G. Voirin, Biosens. Bioelectron., 24, 3340 (2009).

13. W. de Keizer, M.E. Bienenmann-Ploum, A.A. Bergwerff, A.A. Bergwerff and W. Haasnoot, Anal. Chim. Acta, 620, 142 (2008).

14. W. Haasnoot, M. Bienenmann-Ploum and F. Kohen, Anal. Chim. Acta, 483, 171 (2003).

15. C.Y. Hao, X.M. Zhao and P. Yang, TRAC-Trends Anal. Chem., 26, 569 (2007).

TABLE-2

REGRESSION EQUATIONS AND DETECTION LIMITS OF THE ANALYTES ${ }^{\mathrm{a}}$

\begin{tabular}{cccccc}
\hline Analyte & Regression equation & Correlation coefficient & Linear range $(\mu \mathrm{mol} / \mathrm{L})$ & LOD $(\mu \mathrm{mol} / \mathrm{L})$ & $\mathrm{LOQ}(\mu \mathrm{mol} / \mathrm{L})$ \\
\hline SMZ & $\mathrm{y}=14.79 \mathrm{x}+1.06$ & 0.9823 & $0.05-1.25$ & 0.02 & 0.05 \\
SMR & $\mathrm{y}=13.77 \mathrm{x}+1.17$ & 0.9816 & $0.10-1.25$ & 0.04 & 0.10 \\
SMX & $\mathrm{y}=25.33 \mathrm{x}+1.30$ & 0.9900 & $0.05-1.25$ & 0.01 & 0.05 \\
\hline
\end{tabular}

${ }^{a}$ MCE-LIF conditions were the same as in Fig. 4c. ${ }^{b}$ In the regression equation, $x$ value was the concentration of analytes $(\mu \mathrm{mol} / \mathrm{L})$ and $y$ value was the fluorescence intensity $(\mathrm{mV})$. 
16. V.B. Reeves, J. Chromatogr. B, 723, 127 (1999).

17. C. Akay and S.A. Ozkan, J. Pharm. Biomed. Anal., 30, 1207 (2002).

18. N. Takeda and Y. Akiyama, J. Chromatogr., 607, 31 (1992).

19. E.P. Tolika, V.F. Samanidou and I.N. Papadoyannis, Curr. Pharm. Anal., 6, 198 (2010).

20. Y.N. Ni, Z.B. Qi and S. Kokot, Chemometrics Intell. Lab. Syst., 82, 241 (2006).

21. D.C. Duffy, J.C. McDonald, O.J. Schueller and G.M. Whitesides, Anal. Chem., 70, 4974 (1998).

22. L. Martynova, L.E. Locascio, M. Gaitan, G.W. Kramer, R.G. Christensen and W.A. MacCrehan, Anal. Chem., 69, 4783 (1997).

23. A. van den Berg and T.S.J. Lammerink, Top. Curr. Chem., 194, 21 (1998).

24. C.F. Duffy, B. MacCraith, D. Diamond, R. O'Kennedy and E.A. Arriaga, Lab Chip, 6, 1007 (2006).

25. K.S. Kumar and S.H. Kang, Electrophoresis, 28, 4247 (2007)
26. H.G. Lee, K.S. Kumar, J. Soh, Y.-S. Cha and S.H. Kang, Anal. Chim. Acta, 619, 94 (2008).

27. L.J. Jin, B.C. Giordano and J.P. Landers, Anal. Chem., 73, 4994 (2001).

28. B.C. Giordano, L.J. Jin, A.J. Couch, J.P. Ferrance and J.P. Landers, Anal. Chem., 76, 4705 (2004).

29. Y.H. Xu, J. Li and E.K. Wang, Electrophoresis, 29, 1852 (2008).

30. L.L. Wang, J. Wu, Q. Wang, C. He, L. Zhou, J. Wang and Q. Pu, J. Agric. Food Chem., 60, 1613 (2012).

31. Q.C. Chu, D.L. Zhang, J.Y. Wang and J.N. Ye, J. Sci. Food Agric., 89, 2498 (2009).

32. Z.H. Wang, S.X. Zhang, J.Z. Shen and A.E. Sergei, Chinese J. Anal. Chem., 35, 819 (2007).

33. Z. Papai and T.L. Pap, J. Chromatogr. A, 953, 31 (2002).

34. C. West and E. Lesellier, J. Chromatogr. A, 1087, 64 (2005).

35. Q.L. Zhang, H.Z. Lian, W.H. Wang and H.-Y. Chen, J. Chromatogr. A, 1098, 172 (2005). 